\title{
Heritable alteration in salt-tolerance in rice induced by introgression from wild rice (Zizania latifolia)
}

\author{
Chunwu Yang ${ }^{1}$, Tianyuan Zhang ${ }^{1}$, Huan Wang ${ }^{1}$, Na Zhao ${ }^{2}$ and Bao Liu*
}

\begin{abstract}
Background: Introgression as a means of generating phenotypic novelty, including altered stress tolerance, is increasingly being recognized as common. The underlying basis for de novo genesis of phenotypic variation in the introgression lines remains largely unexplored. In this investigation, we used a rice line (RZ35) derived from introgressive hybridization between rice (Oryza sativa L.) and wild rice (Zizania latifolia Griseb.), along with its rice parental line (cv. Matsumae) as the experimental materials. We compared effects of salt stress on growth, ion homeostasis, and relevant gene expression between $R Z 35$ and Matsumae, to explore possible mechanisms of heritable alteration in stress tolerance induced by the introgression.

Results: Contrary to our expectation, the results showed that the inhibitory effect of salt stress on growth of RZ35 was significantly greater than that of Matsumae. We further found that a major underlying cause for this outcome is that the introgression process weakened the capacity in $\mathrm{Na}^{+}$exclusion under the salt stress condition, and hence, escalated the injuries of $\mathrm{Na}^{+}$and $\mathrm{Cl}^{-}$in shoots of $R Z 35$. Accordingly, based on q-RT-PCR analysis, four genes known to be involved in the $\mathrm{Na}^{+}$exclusion, i.e., OsHKT1,5, OsSOS1, OsCIPK24 and OsCBL4, were found to be significantly down-regulated in roots of $R Z 35$ relative to its rice parental line under the salt stress condition, thus implicating a gene expression regulation-based molecular mechanism underlying the difference in salt stress-tolerance between the introgression line and its rice parental line.
\end{abstract}

Conclusions: We show that introgression represents a potent means for rapidly generating de novo heritable variations in physiological traits like stress tolerance in plants, although the direction of the alteration appears unpredictable.

\section{Background}

Interspecific hybridization plays a pervasive role in genome evolution through the formation of homoploid hybrids, allopolyploids and introgressants (Ainouche et al. 2004; Hochholdinger and Hoecker 2007; Lippman and Zamir 2007; Soltis and Soltis 2009). Introgressive hybridization once being considered as "unsuccessful hybridization" turned out as frequent incidents in natural plant populations (Arnold 2004). Introgression has the potential to allow adaptation to evolve at rates that may considerably exceed those possible for nonhybridizing populations that are dependent on random

\footnotetext{
* Correspondence: baoliu@nenu.edu.cn

${ }^{1}$ Key laboratory of Molecular Epigenetics of MOE, Northeast Normal University, Changchun 130024, China

Full list of author information is available at the end of the article
}

mutation for genetic novelty (Barton 2001). For example, Whitney et al. (2010) demonstrated that introgression had altered multiple aspects of the Helianthus annuus phenotypes in an adaptive manner, affected traits relevant to adaptation to both biotic and abiotic environments (Whitney et al. 2010). In plant breeding, introgression of uncharacterized DNA segments from a wild species into a cultivated variety is a commonly used approach. Intriguingly, it is recently recognized that introgression not only produces novel traits via the expected transfer from one parental species to another and genic interaction between parental genomes, but may also generate de novo genetic and epigenetic variations (Ainouche et al. 2004; Wang et al. 2005; Chapman and Abbott 2010). Nevertheless, the underlying basis for the de novo genesis of heritable phenotypic variation via 
introgression remains largely unknown (Baack and Rieseberg 2007; Chapman and Abbott 2010).

Under natural habitat, plants are constantly exposed to biotic or abiotic stress conditions such as pathogen and insect infestation, drought, salinity, and high- or low temperatures. Of these stress conditions, salinity is a widespread environmental problem and an important factor limiting agricultural productivity of many crops. In this study, we chose a rice line derived from introgressive hybridization with wild rice (Zizania latifolia Griseb.) as the experimental material. Z. latifolia grows luxuriantly around paddy fields, and represents a potentially valuable tertiary gene pool for rice improvement (Abedinia et al. 2000). Although the two species are sexually incompatible (Abedinia et al. 2000), we have successfully constructed a set of rice introgressants containing only minute amounts of $Z$. latifolia genomic DNA by a novel sexual hybridization approach (Liu et al. 1999; Shan et al. 2005). Using both amplified fragment length polymorphism (AFLP) analysis (Wang et al. 2005) and gel-blotting (Shan et al. 2005), we documented presence of Zizania species-specific DNA segments in the introgression lines including the one (RZ35) used in this study. Moreover, we showed that these introgression lines contained an array of genetic and epigenetic variations that occurred de novo including rampant mobilization of several transposable elements endogenous to the rice genome (Liu et al. 2004; Shan et al. 2005; Wang et al. 2005). Accordingly, field tests showed that the introgressants exhibited heritable and novel morphological characteristics in multiple traits compared with their rice parental cultivar Matsumae (Shan et al. 2005; Wang et al. 2005). Of these introgressants, one (named $R Z 35$ ) is of exceptional interest as it exhibited multiple novel phenotypic traits compared with its rice parental line Matsumae. For example, compared with Matsumae, RZ35 showed changes in nitrogen use efficiency, prolonged phenophase, and enhanced resistance to the blast disease (Shan et al. 2005; Wang et al. 2005). However, the physiological and molecular mechanisms of these interesting phenotypic alterations remained unknown.

Salt stress in soil generally involves osmotic stress and ion-induced injury, and $\mathrm{Na}^{+}$is the main toxic ion in salinized soil. The extent of tolerance by plants to $\mathrm{Na}^{+}$ stress depends on at least three processes: compartmentalization (at cellular and/or tissue levels), exclusion (from roots into the rhizosphere) and transportation (in vasculatures) of the ions. In Arabidopsis, the salt overly sensitive protein 1 (SOS1) functions in $\mathrm{Na}^{+}$exclusion from root epidermal cells into the rhizosphere, which also plays a role in retrieving $\mathrm{Na}^{+}$from the xylem stream under severe salt stress (Shi et al. 2002). The $\mathrm{Ca}^{2+}$-responsive AtSOS3-AtSOS2 (AtCIPK24-AtCBL4) protein kinase pathway mediates regulation of the expression and activities of $\mathrm{Na}^{+}$transporters such as AtSOS1 and AtNHX, a $\mathrm{Na}^{+} / \mathrm{H}^{+}$exchanger that mediates $\mathrm{Na}^{+}$ compartmentalization into vacuoles ( $\mathrm{Zhu}$ 2003). The rice SOS salt tolerance pathway has been identified and its functions have been shown as similar to that of the SOS pathway in Arabidopsis (Martínez-Atienza et al. 2007). In Arabidopsis and some other plant species, the $\mathrm{Na}^{+} / \mathrm{H}^{+}$exchanger (NHX) family has been shown to function in $\mathrm{Na}^{+}$ compartmentalization into vacuoles (Munns and Tester 2008). In addition, some members of the high affinity $\mathrm{K}^{+}$transporter (HKT) family, such as OsHKT1;5 and AtHKT1;1, mediate $\mathrm{Na}^{+}$exclusion from shoots via $\mathrm{Na}^{+}$removal from the xylem sap (Horie et al. 2009; Negrão et al. 2011).

Given the previously observed multiple phenotypic variations in the introgression line RZ35, describe above, we were interested to explore whether a particular physiological trait, i.e., tolerance to salinity, was altered in this line relative to its rice parental line (Matsumae). For this purpose, we compared effects of salt stress on growth, ion content, and expression level of several genes related to $\mathrm{K}^{+} / \mathrm{Na}^{+}$metabolism between $R Z 35$ and Matsumae. We found that relative to Matsumae, the salt tolerance trait in RZ5 was significantly compromised due to weakened capacity in $\mathrm{Na}^{+}$exclusion under the salt stress condition, and hence, escalated the injuries of $\mathrm{Na}^{+}$and $\mathrm{Cl}^{-}$in shoots. Accordingly, four genes known to be involved in the $\mathrm{Na}^{+}$exclusion, i.e., OsHKT1;5, OsSOS1, OsCIPK24 and OsCBL4, were found to be significantly down-regulated in roots of $R Z 35$ relative to its rice parental line under the salt stress condition, thus implicating a gene expression regulation-based molecular mechanism underlying the difference in salt tolerance between the introgression line and its rice parental line.

\section{Results}

The Tolerance to Salt Stress Was Compromised in Introgression Line RZ35 Relative to Its Rice Parental Line Matsumae

Figure 1 shows that the inhibitory effect of salt stress on growth of the introgression line RZ35 was greater than that of Matsumae at the seedling stage. Furthermore, a survivorship assay showed that under unstressed control condition, both lines had 100\% survival rate, while under salt stress condition $(100 \mathrm{mM} \mathrm{NaCl}$ for $13 \mathrm{~d})$, the survival rate of $R Z 35$ was only $25.3 \%$, and that of Matsumae was $88 \%$ (Figure 2). The membrane damage of salt stress could be reflected by the MDA (malondialdehyde) content, with a higher MDA content denoting a stronger harm of salt stress of the membrane. Although the salt stress increased the electrolyte leakage rates and MDA contents of both lines, the values of $R Z 35$ were 


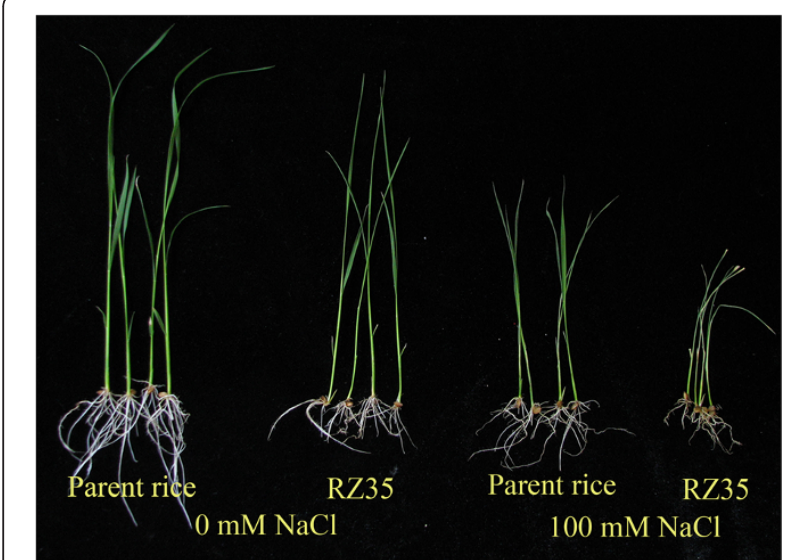

Figure 1 Effects of salt stress on growth in the introgression line $R Z 35$ and its rice parental line, Matsumae. 14-day-old seedlings were subjected to salt stress $(100 \mathrm{mM} \mathrm{NaCl})$ for $5 \mathrm{~d}$. The values shown are the means ( \pm SE) of three biological replicates. Different letters above bars represent significantly different, according to least significant difference $(\mathrm{LSD})$ test $(P<0.05)$.

significantly higher than Matsumae under salt stress (Figure 2, $P<0.05$ ). These results established that the salt tolerance of RZ35 was lower than Matsumae at the seedling stage.

Differential Accumulation of lons between Introgression Line $R Z 35$ and Its Rice Parental Line Matsumae

Salt stress increased contents of $\mathrm{Na}^{+}$and $\mathrm{Cl}^{-}$and $\mathrm{Na}^{+} / \mathrm{K}$ ${ }^{+}$ratio, and decreased content of $\mathrm{K}^{+}$(Figures 3 and 4). When the rice seedlings were subjected to salt stress for $6 \mathrm{~h}$ and $24 \mathrm{~h}$, the $\mathrm{Na}^{+}, \mathrm{Na}^{+} / \mathrm{K}^{+}$and $\mathrm{Cl}^{-}$of $\mathrm{RZ35}$ were similar to Matsumae. However, at $48 \mathrm{~h}$ of salt stress, the $\mathrm{Na}^{+}, \mathrm{Na}^{+} / \mathrm{K}^{+}$, and $\mathrm{Cl}^{-}$in shoots of $R Z 35$ were higher than those of Matsumae (Figures 3 and $4, P<0.05$ ), while their values in roots of $R Z 35$ were lower than those of Matsumae (Figures 3 and $4, P<0.05$ ). The difference between the two lines for $\mathrm{K}^{+}$accumulation was minimal and insignificant (Figures 3C-D). A higher selective transport capacity (ST) indicated stronger capacity by roots to control the transportation of $\mathrm{Na}^{+}$from root to shoot. The ST value was correlated negatively with the $\mathrm{Na}^{+}$content in rice shoots (Figure $3 \mathrm{H}, P<0.0001$ ). The ST value of RZ35 was lower than Matsumae at $48 \mathrm{~h}$ under salt stress (Figure $3 G, P<0.05$ ).

\section{Altered Expression of the Salt Overly Sensitive (SOS)} Pathway and the $\mathrm{Na}^{+} / \mathrm{H}^{+}$Exchanger (NHX) Gene Families in Introgression Line $R Z 35$

Salt stress stimulated the expression of 5 genes of the salt overly sensitive (SOS) pathway: OsSOS1, OsCIPK24, OsCBL4, OsNHX1 and OsNHX2 and the $\mathrm{Na}^{+} / \mathrm{H}^{+}$exchanger (NHX) gene families known to be involved in
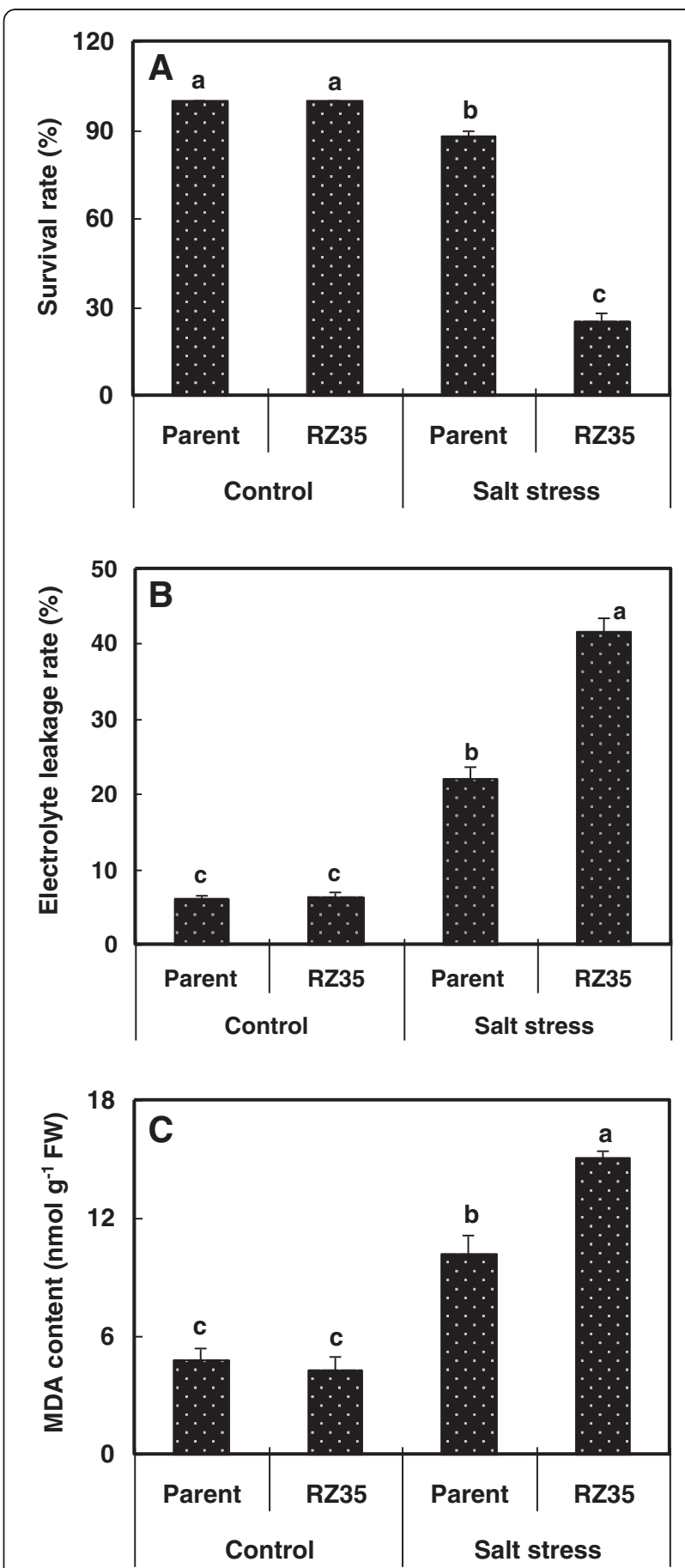

Figure 2 Effects of salt stress on survival rate, MDA (malondialdehyde) content and electrolyte leakage rate in the introgression line RZ35 and its rice parental line, Matsumae. 14day-old seedlings were subjected to salt stress (100 mM NaCl). When the seedlings were subjected to salt stress for $5 \mathrm{~d}$, the MDA content and electrolyte leakage rate of shoots were mensurated. When the seedlings were subjected to salt stress for $13 \mathrm{~d}$, the survival rates were calculated. The values shown are the means ( \pm SE) of three biological replicates. Different letters above bars represent significantly different, according to least significant difference (LSD) test $(P<0.05)$. 

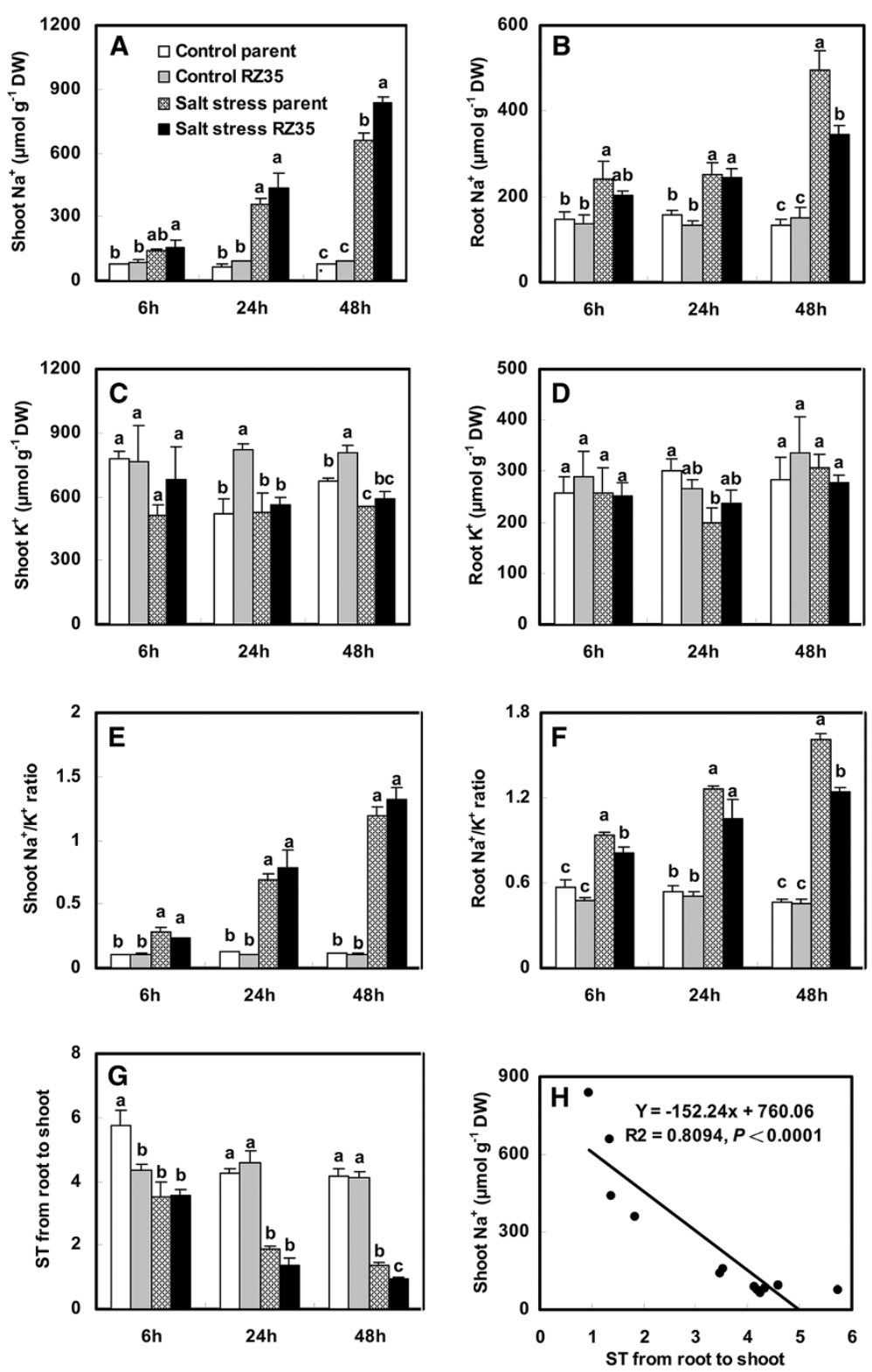

Figure 3 Effects of salt stress on $\mathrm{Na}^{+}, \mathrm{K}^{+}, \mathrm{Na}^{+} / \mathrm{K}^{+}$and $\mathrm{ST}$ in the introgression line $R Z 35$ and its rice parental line, Matsumae. The values shown are the means $( \pm \mathrm{SE}$ ) of three biological replicates. Means followed by different letters among treatments at same time point are significantly different, according to least significant difference (LSD) test $(P<0.05)$. 14-day-old seedlings were subjected to salt stress (100 mM $\mathrm{NaCl}$ ) for $6 \mathrm{~h}, 24 \mathrm{~h}$ and $48 \mathrm{~h}$. ST, selective transport capacity by different parts of plant for $\mathrm{K}^{+}$over $\mathrm{Na}^{+}$. ST, selective transport capacity by different parts of plant for $\mathrm{K}^{+}$over $\mathrm{Na}^{+}$. ST (root/shoot) $=\left(\mathrm{Na}^{+} / \mathrm{K}^{+}\right.$in root $) /\left(\mathrm{Na}^{+} / \mathrm{K}^{+}\right.$in shoot). The correlation analysis between ST and shoot $\mathrm{Na}^{+}$content was performed $(\mathbf{H})$.

salt-tress response in shoots and roots in rice (Figures 5 and 6). Under salt stress, the steady-state transcript levels of OsSOS1, OsCIPK24, OsCBL4 and OsNHX2 in the shoots of $R Z 35$ were significantly lower than those in Matsumae at $6 \mathrm{~h}$. The expression level of OsNHX1 in shoots of RZ35 was higher than that in Matsumae at $48 \mathrm{~h}$ under salt stress (Figure 6A, $P<0.05$ ). The expression levels of OsSOS1, OsCIPK24, OsCBL4, OsNHX1 and
OsNHX2 in roots of RZ35 were lower than those of Matsumae under salt stress (Figures 5 and 6).

\section{Altered Expression of the High Affinity $\mathrm{K}^{+}$Transporter (HKT) Gene Family}

Salt stress increased the steady-state transcript levels of OsHKT1;1, OsHKT1;3 and OsHKT1;5 in roots of both lines. Salt stress increased the expression levels of 

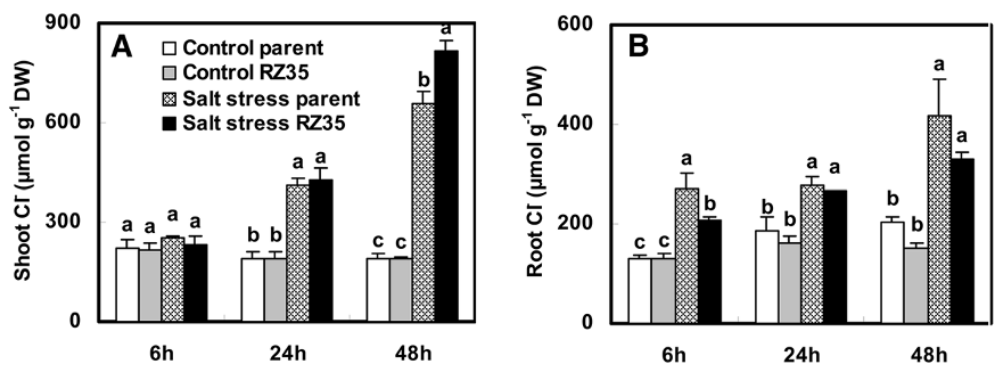

Figure 4 Effects of salt stress on $\mathrm{Cl}^{-}$contents in the introgression line $R Z 35$ and its rice parental line, Matsumae. The values shown are the means $( \pm$ SE) of three biological replicates. Means followed by different letters among treatments at same time point are significantly different, according to least significant difference (LSD) test $(P<0.05)$. 14-day-old seedlings were subjected to salt stress (100 mM NaCl) for $6 \mathrm{~h}, 24 \mathrm{~h}$ and $48 \mathrm{~h}$.

OsHKT2;1 in roots of Matsumae, and decreased its expression level in roots of $R Z 35$. Under salt stress, the expression levels of OsHKT1;1, OsHKT1;3 and OsHKT2;1 in roots of $R Z 35$ were lower than Matsumae (Figure 7, $P<0.05)$. The expression levels of OsHKT1;5 in shoots at all three time-points and at $48 \mathrm{~h}$ in roots of $R Z 35$ were lower than Matsumae (Figure 7).

\section{Altered Expression of the Low Affinity $K^{+}$Transporter 1 (AKT1) and KUP/HAK/KT K $K^{+}$Transporter (HAK) Gene}

Families

Under salt stress, the steady-state transcript level of OsAKT1 in shoots of RZ35 was lower than that in Matsumae at $6 \mathrm{~h}$. The expression level of OsAKT1 in roots of RZ35 was higher than that in Matsumae at $6 \mathrm{~h}$ and
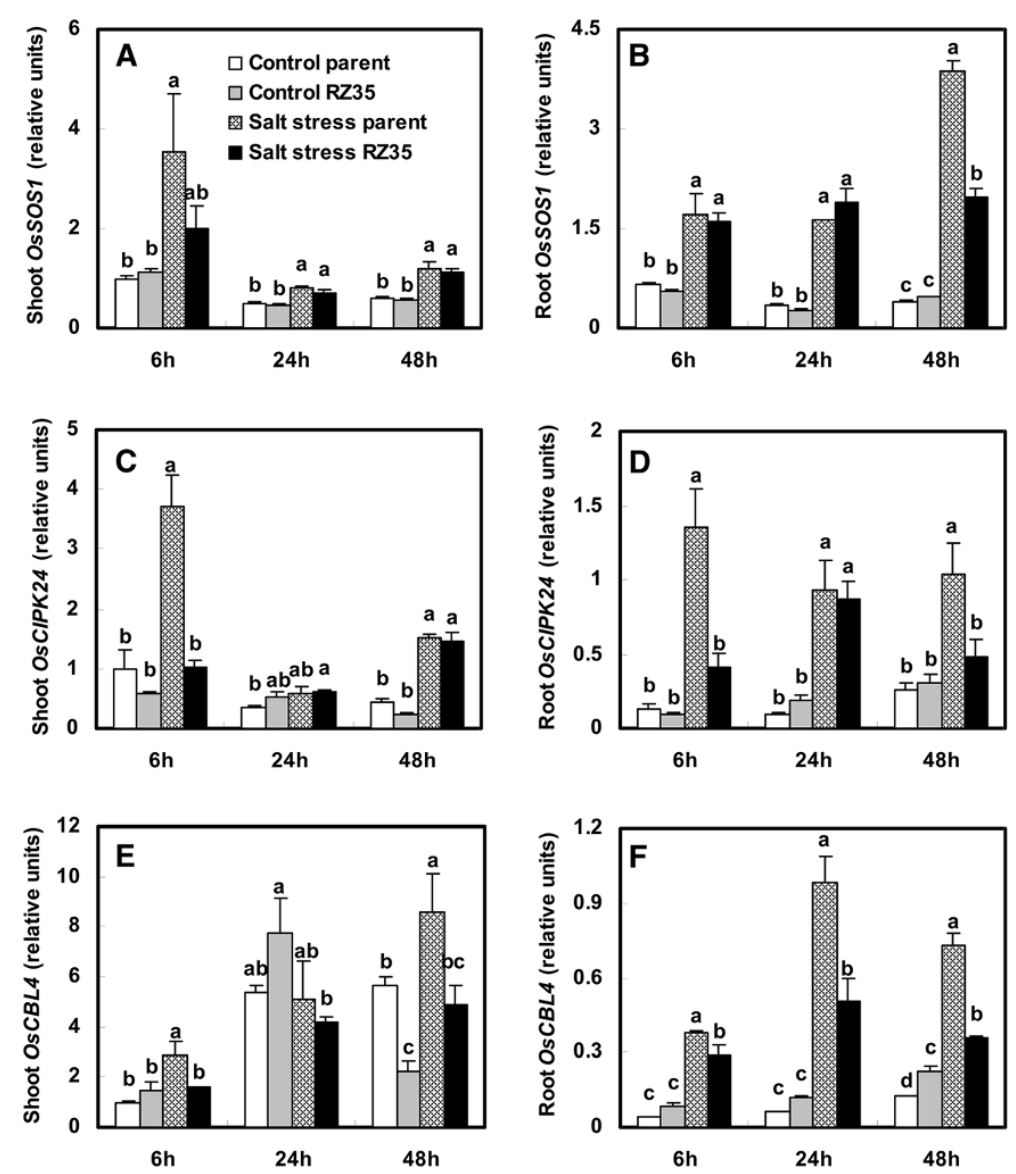

Figure 5 Effects of salt stress on the expression of OsSOS1, OsCIPK24 and OsCBL4 in the introgression line RZ35 and its rice parental line, Matsumae. The values shown are the means ( \pm SE) of three biological replicates. Means followed by different letters among treatments at same time point are significantly different, according to least significant difference (LSD) test $(P<0.05)$. 14-day-old seedlings were subjected to salt stress (100 mM NaCl) for 6 h, $24 \mathrm{~h}$ and $48 \mathrm{~h}$. 

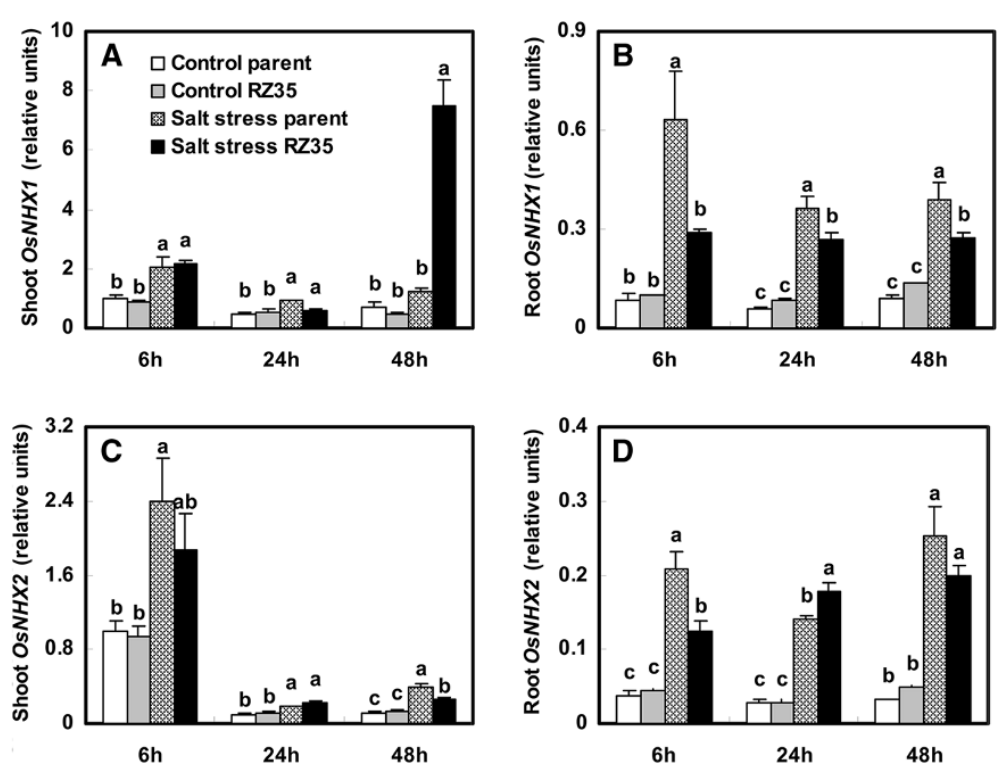

Figure 6 Effects of salt stress on the expression of OsNHX1 and OsNHX2 in the introgression line RZ35 and its rice parental line, Matsumae. The values shown are the means $( \pm$ SE) of three biological replicates. Means followed by different letters among treatments at same time point are significantly different, according to least significant difference (LSD) test $(P<0.05)$. 14-day-old seedlings were subjected to salt stress (100 mM NaCl) for $6 \mathrm{~h}, 24 \mathrm{~h}$ and $48 \mathrm{~h}$.

$24 \mathrm{~h}$ (Figure $8, P<0.05$ ). Salt stress strongly stimulated the expression of all members of the OsHAK family in roots of both lines. Under salt stress, the expression levels of OSHAK7 and OsHAK10 in roots of RZ35 were lower than those in Matsumae, and the expression level of OsHAK16 in roots of RZ35 was higher than that of Matsumae at $24 \mathrm{~h}$ and $48 \mathrm{~h}$ (Figure $8, P<0.05$ ).

\section{Discussion}

That introgression could enhance stress tolerance or adaptability has been documented by numerous studies. For example, the introgression from a wild rice species (Oryza rufipogon Griff.) increased the drought tolerance of the recipient rice cultivar (Zhang et al. 2006). The introgression from Thinopyrum ponticum (Chen et al. 2004) and Th. hessarahicum (King et al. 1997) improved salt-tolerance of wheat, and the introgression of the PcINO1 gene from Porteresia coarctata conferred salt tolerance to tobacco plants (Das-Chatterjee et al. 2006). The introgression from wild rice species increased yield of rice under drought condition (Bimpong et al. 2011; Kato et al. 2011). The introgression of SUB1, a major submergence-tolerance QTL, enhanced the yield of the recipient rice cultivar under submergence condition (Singh et al. 2009). It should be pointed out that in all these examples, the altered traits could be explained by either direct transfer and/or allelic or non-allelic genic interactions (e.g., epistasis) between the two parental species. In contrast, in our case, because the amount of genetic introgression from Zizania latifolia is minute on one hand, and extensive genetic and epigenetic de novo variations occurred on the other (Liu et al. 2004; Shan et al. 2005; Wang et al. 2005), it is most likely that the altered trait (salt tolerance) occurred de novo. Also, in contrast with the above examples, we observed the trait alteration in an opposite direction (Figures 1 and 2), that is, the introgression by $Z$. latifolia has reduced salt tolerance in the introgression line (RZ35) compared with its rice parental line (Matsumae).

Lower $\mathrm{Na}^{+}$and higher $\mathrm{K}^{+}$in the cytoplasm are essential for maintaining kinetic activity of a number of enzymes (Munns and Tester 2008). $\mathrm{Na}^{+}$enters plant cells principally through $\mathrm{K}^{+}$pathways (Blumwald 2000). The similarity of the hydrated ionic radii of $\mathrm{Na}^{+}$and $\mathrm{K}^{+}$ make them difficult to be discriminated from each other, and this constitutes the basis of $\mathrm{Na}^{+}$toxicity (Blumwald 2000). $\mathrm{Na}^{+}, \mathrm{Cl}^{-}$and $\mathrm{Na}^{+} / \mathrm{K}^{+}$are important physiological selection criteria for salt tolerance in plants (Ashraf 2004). Our results indicated that, when plants were subjected to salt stress for $48 \mathrm{~h}$, the $\mathrm{Na}^{+}, \mathrm{Cl}^{-}$and $\mathrm{Na}^{+} / \mathrm{K}^{+}$ ratio in shoots of the introgressant $(R Z 35)$ were higher than those of its parental line (Matsumae), while their values in roots of the introgressant were lower than those in the rice parental line (Figures 3 and 4). This suggested that the introgression has strongly influenced the ion accumulation of the recipient rice under the salt stress condition (Figures 3 and 4), and escalated the injuries of $\mathrm{Na}^{+}$and $\mathrm{Cl}^{-}$in shoots. This might be the major cause for the damage of salt stress on the introgressant RZ35 at the physiological level, which was much more 

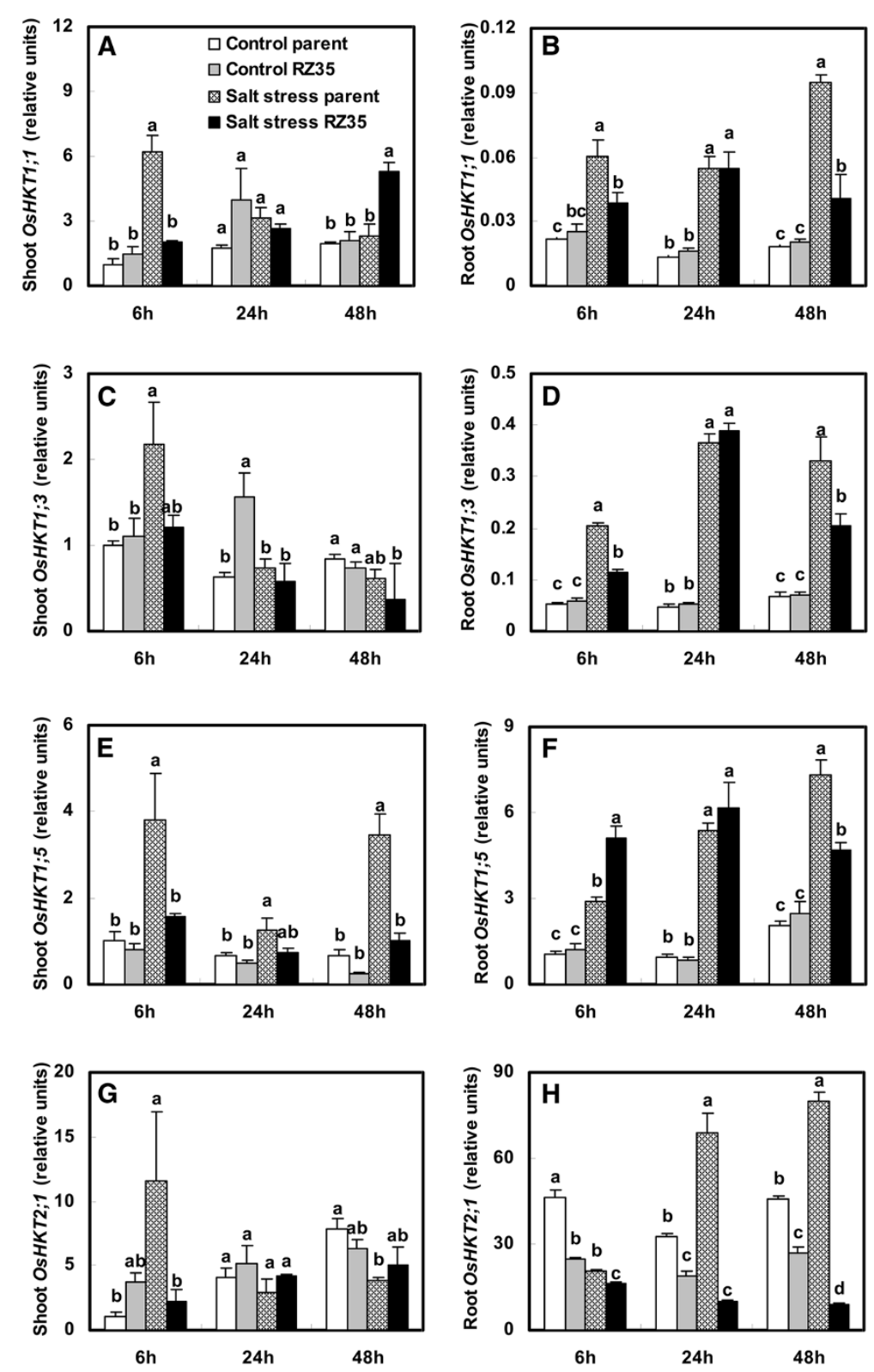

Figure 7 Effects of salt stress on the expressions of OsHKT1;1, OsHKT1;3, OsHKT1;5 and OsHKT2;1 in rice-Z. latifolia introgressant (RZ35) and its rice parental line (Matsumae). The values shown are the means $( \pm$ SE) of three biological replicates. Means followed by different letters among treatments at same time point are significantly different, according to least significant difference (LSD) test $(P<0.05)$. 14-day-old seedlings were subjected to salt stress (100 mM NaCl) for 6 h, $24 \mathrm{~h}$ and $48 \mathrm{~h}$.

severe than that of the parental line. We suspected that the larger amount of accumulation of $\mathrm{Na}^{+}$in rice shoots induced by the introgression might be related to the expression alteration of genes related to $\mathrm{Na}^{+} / \mathrm{K}^{+}$balance.

Indeed, We found that salt stress strongly stimulated the expression of the OsSOS1, OsCIPK24, OsCBL4, $O s N H X$ and $O s H K T$ gene families in rice (Figures 5, 6, 7). These genes have been shown to play vital roles in conditioning salt tolerance in rice (Negrão et al. 2011). Relative to its rice line (Matsumae), the introgressant (RZ35) showed significantly lower levels of expression of OsSOS1, OsCIPK24, and OsCBL4 in both shoots and roots under salt stress (Figure 5). Also, the introgressant (RZ35) showed lower expression levels of OsNHX2, OsHKT1;1, OsHKT1;3 and OsHKT2;1 in roots, and lower expression level of OsHKT1;5 in both shoots and roots (at $48 \mathrm{~h}$ ) than Matsumae under salt stress (Figures 6 and 7). It was widely recognized that OsSOS1 played important roles in $\mathrm{Na}^{+}$exclusion from roots into the rhizosphere; OsSOS1 and OsHKT1;5 played important roles in the control of 

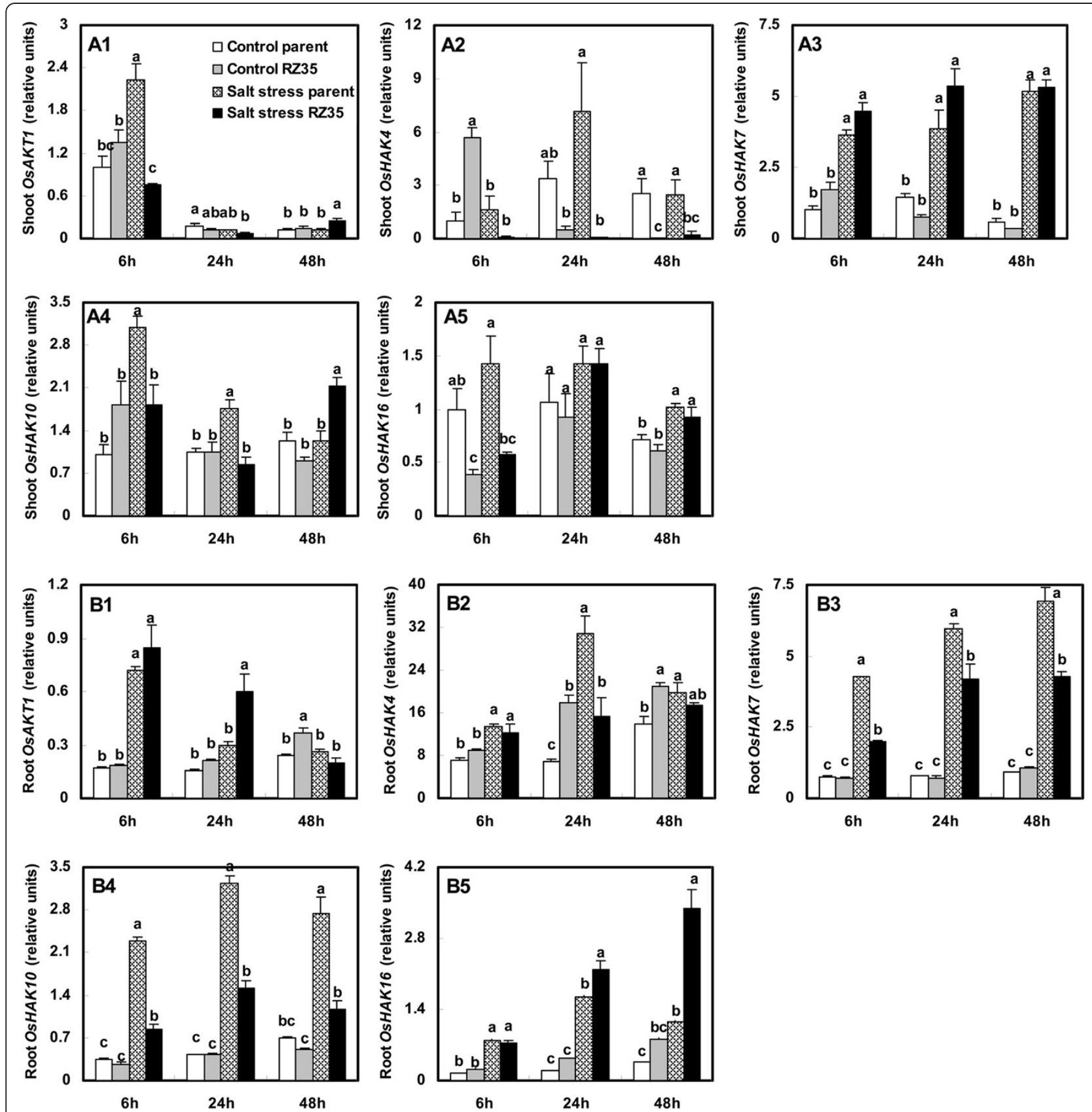

Figure 8 Effects of salt stress on the expression of OsHAK family members and OsAKT1 in rice-Z. latifolia introgressant (RZ35) and its rice parental line (Matsumae). The values shown are the means $( \pm \mathrm{SE})$ of three biological replicates. Means followed by different letters among treatments at same time point are significantly different, according to least significant difference (LSD) test $(P<0.05)$. 14-day-old seedlings were subjected to salt stress (100 mM NaCl) for 6 h, $24 \mathrm{~h}$ and $48 \mathrm{~h}$.

long-distance transport from roots to shoots and contributed to $\mathrm{Na}^{+}$exclusion from shoots to the roots (Shi et al. 2002; Ren et al. 2005; Munns and Tester 2008; Horie et al. 2009). For example, Shi et al. (2002) clearly demonstrated that SOS1 was critical for controlling long-distance $\mathrm{Na}^{+}$ transport from root to shoot, and SOS1 functioned in retrieving $\mathrm{Na}^{+}$from the xylem stream under severe salt stress (Shi et al. 2002). Ren et al. (2005) also showed that
OsHKT1;5 mediates $\mathrm{Na}^{+}$unloading from xylem vessels at the plasma membrane of xylem parenchyma cells, namely OsHKT1;5 mediated sodium exclusion from leaves or shoots (Ren et al., 2005), which has been widely accepted (Ren et al. 2005; Negrão et al. 2011). The down-regulation of SOS1, CIPK24, CBL4 and OsHKT1;5 may have increased $\mathrm{Na}^{+}$content in shoots because their downregulation decreased the frequency of $\mathrm{Na}^{+}$exclusion from 
shoots or roots (Ren et al. 2005; Munns and Tester 2008; Negrão et al. 2011). Together, these data strongly suggested that, under salt stress, the introgression increased the $\mathrm{Na}^{+}$content in shoots of of the introgression line via down-regulation of OsSOS1, OsCIPK24, OsCBL4 and OsHKT1;5. This suggested that the introgression modified the capacity of the rice roots to control the transportation of $\mathrm{Na}^{+}$from roots to shoots via a gene expression regulation. This conclusion was also supported by the ion selective transport capacity (ST) results. The ST value of the introgressant was lower than that of the rice parental line at $48 \mathrm{~h}$ under salt stress (Figure 3G). Our results may explain why the $\mathrm{Na}^{+}$content in shoots of the introgressant was higher than that of the rice parental line and why in roots of the introgressant it was lower than that in the parental line under salt stress (Figure 3). Furthermore, the introgression also greatly affected the $\mathrm{K}^{+}$ metabolism (Figure $3 \mathrm{C}$ and $\mathrm{D}$ ). Trans-membrane $\mathrm{K}^{+}$ movements in plants are mediated by several types of channels, including the AKT family, and by transporters that belong to two families, KcsA-TRK (HKT) and KUP/ HAK/KT (HAK) (Bañuelos et al. 2002; Amrutha et al. 2007). Figure 8 shows that the introgression strongly affected the expression of the OsHAK gene family and OsAKT1. The expression levels of OsHAK7 and OsHAK1O in roots of the introgressant were lower than those of the parental rice line under salt stress, which might be useful to the $\mathrm{K}^{+}$supply of introgressant shoots.

In summary, our results showed that the introgression from $Z$. latifolia affected growth, salt stress response and metabolism of the recipient rice cultivar. It will be interesting to elucidate by what means the introgression process (rather than the introgression per se) would have concomitantly affected numerous metabolic pathways or links such as $\mathrm{K}^{+}$metabolism (changed the expressions of OsHAK family and OsAKT1), $\mathrm{Na}^{+}$control, protein kinase (OsCIPK24), and $\mathrm{Ca}^{2+}$ binding protein (OsCBL4). One conceivable possibility is the extensive epigenetic remodeling in the form of altered DNA methylation that occurred in many genomic loci in this introgression line is responsible for the down-regulated expression of these analyzed genes under the salt tress condition (Liu et al. 2004). It has been established that altered DNA methylation at critical regions of a master regulatory gene may exert profound effects on the expression of many downstream target genes (Lukens and Zhan 2007; Chinnusamy and Zhu 2009; Doerfler 2011). An epigenetic underpin may also explain the differential effect by the introgression on gene expression in different tissues, e.g., leaf vs. root of $R Z 35$. Further studies are needed to investigate this possibility.

\section{Conclusions}

In summary, our results showed that the introgression from $Z$. latifolia affected growth, salt stress response and metabolism of the recipient rice cultivar. Contrary to our expectation, the results showed that the inhibitory effect of salt stress on growth of RZ35 was significantly greater than that of Matsumae. We further found that a major underlying cause for this outcome is that the introgression process weakened the capacity in $\mathrm{Na}^{+}$exclusion under the salt stress condition, and hence, escalated the injuries of $\mathrm{Na}^{+}$and $\mathrm{Cl}^{-}$in shoots of RZ35. Accordingly, four genes known to be involved in the $\mathrm{Na}^{+}$exclusion, i.e., OsHKT1;5, OsSOS1, OsCIPK24 and $O s C B L 4$, were found to be significantly down-regulated in roots of $R Z 35$ relative to its rice parental line under the salt stress condition, thus implicating a gene expression regulation-based molecular mechanism underlying the difference in salt stress-tolerance between the introgression line and its rice parental line.

\section{Methods}

\section{Plant materials}

The introgression line (RZ35) derived from a cross between rice (cv. Matsumae) and Zizania latifolia by a novel, simple approach called "repeated pollination" (Liu et al., 1999; Shan et al., 2005), was used in this study. This stabilized introgressant (at the 10th selfed generation) was homogeneous in phenotype and DNA fingerprinting patterns, and exhibited heritable, novel morphological characteristics in multiple traits compared with its rice parental cultivar Matsumae (Shan et al. 2005; Wang et al. 2005).

\section{Plant growth conditions}

Seeds of the introgressant (RZ35) and its rice parental line Matsumae were germinated in petri dishes for $6 \mathrm{~d}$ in a growth cabinet $\left(28^{\circ} \mathrm{C}\right.$ during the day and $24^{\circ} \mathrm{C}$ during the night, $16 / 8 \mathrm{~h}$ photoperiod at $50 \mu \mathrm{mol} \mathrm{m}^{-2} \mathrm{~s}^{-1}$ ). The seedlings were then transferred to barrels containing $2000 \mathrm{~mL}$ of aerated sterile nutrient solution under hydroponic culture, and the nutrient solution was replaced every two days. The barrels were placed in a growth chamber that was maintained at $27.0 \pm 1^{\circ} \mathrm{C}$ during the day and $22.0 \pm 1^{\circ} \mathrm{C}$ during the night, under a $16 / 8 \mathrm{~h}$ photoperiod at $250 \mu \mathrm{mol} \mathrm{m}{ }^{-2} \mathrm{~s}^{-1}$. The nutrient solution used in this work contained $0.715 \mathrm{mM}$ $\mathrm{NH}_{4} \mathrm{NO}_{3}, \quad 0.16 \mathrm{mM} \quad \mathrm{NaH}_{2} \mathrm{PO}_{4}, 0.323 \mathrm{mM} \quad \mathrm{K}_{2} \mathrm{SO}_{4}$, $0.5 \mathrm{mM} \mathrm{CaCl}_{2}, 0.83 \mathrm{mM} \mathrm{MgSO}_{4}, 0.036 \mathrm{mM}$ Fe-EDTA, $\begin{array}{lllllll}0.1 & \mathrm{mM} & \mathrm{Na}_{2} \mathrm{SiO}_{3}, & 4.55 \mu \mathrm{M} & \mathrm{MnCl}_{2}, & 0.077 \mu \mathrm{M}\end{array}$ $\mathrm{ZnSO}_{4}, 0.078 \mu \mathrm{M} \mathrm{CuSO}_{4}, 9.25 \mu \mathrm{M} \mathrm{H}_{3} \mathrm{BO}_{3}, 0.263 \mu \mathrm{M}$ $\mathrm{H}_{2} \mathrm{MoO}_{4}$, and $\mathrm{pH}=5.2$.

\section{Stress treatment}

After 10 days of growth in hydroponic culture medium, rice plants were subjected to salt stress $(100 \mathrm{mM} \mathrm{NaCl})$ by transferring them to another barrel containing $2000 \mathrm{~mL}$ of the treatment solution amended with the above nutrients 
and $100 \mathrm{mM} \mathrm{NaCl}$. A barrel including 20 seedlings represented one replicate. For each line, 24 barrels of seedlings were randomly divided into 8 sets, three buckets per set. Each barrel was considered as one replicate with three replicates per set. Four sets were used as control (one set per time point), and the remaining four sets were treated with salt stress. Treatment solutions were replaced daily. The nutrient solution without stress salts was used as a control. The seedlings were harvested after treatment for 6,24 , and $48 \mathrm{~h}$ respectively. When plants were subjected to salt stress for $5 \mathrm{~d}$, the plants were photographed to test tolerance of introgressant (RZ35) and its rice parental (cv. Matsumae) to salt stress. Then the electrolyte leakage rate was determined with the ameliorated method of Lutts et al. (1996). One fresh whole plant (shoot) from each barrel was washed three times with deionized water to remove surface adhered electrolytes, then was placed in a closed cuvette containing $20 \mathrm{~mL}$ of deionized water at $25^{\circ} \mathrm{C}$ for $6 \mathrm{~h}$. The electrical conductivity of the solution (EC1) was determined with a conductivity gauge. After this the cuvette was autoclaved at $100^{\circ} \mathrm{C}$ for $20 \mathrm{~min}$, and the electrical conductivity of the solution (EC2) was determined. Electrolyte leakage rate can be defined as follows: Electrolyte leakage rate $(\%)=(E C 1 / E C 2) \times 100$. Remaining plant materials in each barrel were immediately frozen in liquid nitrogen and then stored at $-70^{\circ} \mathrm{C}$ for malondialdehyde (MDA) determination.

\section{Measurements of physiological indices}

The roots and shoots of 10 seedlings in each barrel were immediately frozen in liquid nitrogen and then stored at $-70^{\circ} \mathrm{C}$ for RNA isolation. Another 10 seedlings in each barrel were washed with distilled water, after which the roots and shoots were separated and lyophilized. Then all dry samples of 10 seedlings in each barrel were levigated and mixed for ion measurements. The dried samples of the roots and shoots were digested with $\mathrm{HNO}_{3}$, and the $\mathrm{Na}^{+}$and $\mathrm{K}^{+}$contents were assayed using an atomic absorption spectrophotometer (TAS-990, Purkinje General, Beijing). Dry samples of plant material were treated with $10 \mathrm{~mL}$ deionized water at $100^{\circ} \mathrm{C}$ for $2 \mathrm{~h}$, and the extract was then used to determine the $\mathrm{Cl}^{-}$ content. The $\mathrm{Cl}^{-}$content was determined by ion chromatography (DX-300 ion chromatographic system; AS4A-SC ion-exchange column, CD M-II electrical conductivity detector, mobile phase: $\mathrm{Na}_{2} \mathrm{CO}_{3} / \mathrm{NaHCO}_{3}=$ 1.7/1.8 mM; DIONEX, Sunnyvale, USA). MDA content was determined with the method of Zhao et al. (1994).

\section{Quantitative real-time reverse-transcription (RT)-PCR analysis}

Total RNA was extracted from the shoots and roots of seedlings grown under the salt-stress or non-stress conditions using TRIzol reagent (Invitrogen). The RNA was treated with DNaseI (Invitrogen), reverse-transcribed using SuperScriptTM RNase H-Reverse Transcriptase (Invitrogen), and then subjected to real time PCR analysis using gene-specific primers. The gene-specific primers are listed in Table 1. PCR amplification was conducted with an initial step at $95^{\circ} \mathrm{C}$ for 1 min followed by 40 cycles of $5 \mathrm{~s}$ at $95^{\circ} \mathrm{C}, 10 \mathrm{~s}$ at $60^{\circ} \mathrm{C}$ and $30 \mathrm{~s}$ at $72^{\circ} \mathrm{C}$. Amplification of the target gene was monitored every cycle by SYBR Green. Amplification of the rice $\beta$-actin (GenBank Accession AK101613) mRNA was used as an internal quantitative control (Sripinyowanich et al. 2010;

Table 1 Gene-specific primers used in real time quantitative RT-PCR analysis

\begin{tabular}{|c|c|c|c|}
\hline Gene name & GenBank Accession No. & Forward primer (5/-3/) & Reverse primer (5/-3/) \\
\hline OsNHX1 & AB021878 & GTTCAAGAGTTACAACAAAGCACG & CAGCGGGAATACAAAAGCAG \\
\hline OsNHX2 & AY360145 & ACCAAGACGAAACACCCCTAC & AACCCAGCAACTACTCCAAGAA \\
\hline OsHKT1;1 & AJ491816 & ATTAGCAGAGCACTGTGGAGGAA & CCGACGAACCCGTAGGAAG \\
\hline OsHKT1;3 & AJ491818 & CAGTTCATCTACCAAAACAATCCA & AATACCTCACCACCAATCAGCA \\
\hline OsHKT1,5 & DQ148410 & TGCCACCTTACACCACTITCG & TGCCATACGCACTGATAACCTC \\
\hline OsHKT2;1 & AB061311 & GCATATTCACCCATTCTGGATTCAGT & CGATGGTGATGAGGCTGGAAAGT \\
\hline OsSOS1 & AY785147 & CTCCGTGCTCATAGAATCGC & ATACTCACTCAAGTGGGTCAATACC \\
\hline OsCBL4 & AK101368 & GGCATCGTTCGGATTTCAC & GAGATTCGCCTTTCTGCTGTT \\
\hline OsCIPK24 & AK102270 & AAGAAGCGGGTGGGGAGGT & GCGGTGGTTGAGGATGGTGT \\
\hline OsAKT1 & AY065970 & TACGACCGCCGATACAGAA & CCAAATAAGCCACAAAGAAGG \\
\hline OSHAK4 & AF129485 & CGTTCCCATCCGTCAGTAAA & CAGCCTCTGGTCTGGTTCGTC \\
\hline OsHAK7 & AJ427971 & GAACTCCAACTTCCTCAAGACG & AGATCATGCCGACTTCGACGAG \\
\hline OSHAK10 & AJ427972 & CGCTCTCGGCTGCTTTCCT & TAACCGCCAATCCTGACGC \\
\hline OSHAK16 & AJ427973 & AGCGACTGTGTGCTAAACCC & CATAGATGCCAATCCCTGAGA \\
\hline$\beta$-actin & AK101613 & ATGCCATTCTCCGTCTT & GCTCCTGCTCGTAGTC \\
\hline
\end{tabular}

$\mathrm{NHX}, \mathrm{Na}^{+} / \mathrm{H}^{+}$exchanger; $\mathrm{HKT}$, high affinity $\mathrm{K}^{+}$transporter; HAK, KUP/HAK/KT K ${ }^{+}$transporter; AKT, low affinity $\mathrm{K}^{+}$transporter; SOS, salt overly sensitive. 
Wang et al. 2010). PCR reaction conditions were optimized, after which the amplification efficiencies of each target gene and reference gene were approximately equal. The relative expression of the target genes was measured using the comparative Ct method (Livak and Schmittgen 2001). Real time PCR analyses were conducted at least three times for each sample.

\section{Calculation of ion selective transport capacity}

Values of the selective transport capacity (ST) by different plant parts for $\mathrm{K}^{+}$over $\mathrm{Na}^{+}$were estimated following the equation of Wang et al. (2002) : ST (root/shoot) = $\left(\mathrm{Na}^{+} / \mathrm{K}^{+}\right.$in root $) /\left(\mathrm{Na}^{+} / \mathrm{K}^{+}\right.$in shoot $)$. The bigger the ST value, the stronger the root controls $\mathrm{Na}^{+}$and promotes transport of $\mathrm{K}^{+}$to shoot, indicating a stronger selective transport capacity of the root.

\section{Survival rate}

The seeds of both rice lines were germinated and grown in petri dishes for $6 \mathrm{~d}$ in a growth cabinet $\left(28^{\circ} \mathrm{C}\right.$ during the day and $24^{\circ} \mathrm{C}$ during the night, $16 / 8 \mathrm{~h}$ photoperiod at $50 \mu \mathrm{mol} \mathrm{m} \mathrm{m}^{-2} \mathrm{~s}^{-1}$ ). The seedlings were cultured and stressed using the above methods. After 10 days of growth in hydroponic medium, rice plants were subjected to stresses by transferring them to another barrel containing $2000 \mathrm{~mL}$ of the treatment solution amended with the above nutrients and $100 \mathrm{mM} \mathrm{NaCl}$. A barrel including 50 seedlings represented one replicate, and there were three replicates per treatment. For each rice line, 6 barrels of seedlings were randomly divided into 2 sets, three barrels per set. Each barrel was considered as one replicate with three replicates per set, one set was used as control, and another set was treated with salt stress. The nutrient solution without stress salts was used as a control. The survival rates were calculated after treatment for $13 \mathrm{~d}$.

\section{Statistical analysis}

Statistical analysis of the data was performed using the statistical program SPSS 13.0 (SPSS, Chicago, USA). All data were represented by an average of the three biological replicates and the standard errors (S.E.). The treatment mean values at same time point were compared by post hoc least significant difference (LSD) test. The term significant indicates differences at $P<0.05$.

\footnotetext{
Abbreviations

SOS: Salt overly sensitive; $\mathrm{NHX}: \mathrm{Na}^{+} / \mathrm{H}^{+}$exchanger; HKT: High affinity $\mathrm{K}^{+}$ transporter; HAK: KUP/HAK/KT K ${ }^{+}$transporter; AKT: Low affinity $\mathrm{K}^{+}$transporter; ST: Selective transport for controlling $\mathrm{Na}^{+}$and promoting transport of $\mathrm{K}^{+}$.
}

\section{Competing interests}

The authors declare that this paper have no competing interests.

\section{Authors' contributions}

Conceived and designed the experiments: CY BL. Performed the experiments: CY HW NZ TZ. Analyzed the data: CY BL. Wrote the paper: CY BL. All authors read and approved the final manuscript.

\section{Acknowledgements}

This work was supported by the State Key Basic Research and Development Plan of China (2011CB100205), grants from the National Natural Science Foundation of China (Nos. 30990243 and J1210045), the Programme for Introducing Talents to Universities (B07017), and the Fundamental Research Funds for the Central Universities (Nos. 11QNJJ020 and 10SSXT143).

\section{Author details}

${ }^{1}$ Key laboratory of Molecular Epigenetics of MOE, Northeast Normal University, Changchun 130024, China. ²Department of Agronomy, Jilin Agricultural University, Changchun 130118, China.

Received: 8 July 2012 Accepted: 10 December 2012

Published: 19 December 2012

\section{References}

Abedinia M, Henry RJ, Blakeney AB, Lewin LG (2000) Accessing genes in the tertiary gene pool of rice by direct introduction of total DNA from Zizania palustris (wild rice). Plant Mol Biol Rep 18:133-138

Ainouche ML, Baumel A, Salmon A, Yannic G (2004) Hybridization, polyploidy and speciation in Spartina (Poaceae). New Phytol 161:165-172

Amrutha RN, Sekhar PN, Varshney RK, Kishor P (2007) Genome-wide analysis and identification of genes related to potassium transporter families in rice (Oryza sativa L.). Plant Sci 172:708-721

Arnold ML (2004) Transfer and origin of adaptations through natural hybridization: were Anderson and Stebbins right? Plant Cell 16:562-570

Ashraf M (2004) Some important physiological selection criteria for salt tolerance in plants. Flora 199:361-376

Bañuelos MA, Garciadeblas B, Cubero B, Rodríguez-Navarro A (2002) Inventory and functional characterization of the HAK potassium transporters of rice. Plant Physiol 130:784-795

Baack EJ, Rieseberg LH (2007) A genomic view of introgression and hybrid speciation. Curr Opin Genet Dev 17:513-518

Barton N (2001) The role of hybridization in evolution. Mol Ecol 10:551-568

Bimpong IK, Serraj R, Chin JH, Ramos J, Mendoza EMT, Hernandez JE, Mendioro MS, Brar DS (2011) Identification of QTLs for drought-related traits in alien Introgression lines derived from crosses of rice (Oryza sativa cv. IR64) $\times 0$. glaberrima under lowland moisture stress. J Plant Biol 54:237-250

Blumwald E (2000) Sodium transport and salt tolerance in plants. Curr Opin Cell Biol 12:431-434

Chapman MA, Abbott RJ (2010) Introgression of fitness genes across a ploidy barrier. New Phytol 186:63-71

Chen S, Xia G, Quan T, Xiang F, Jin Y, Chen H (2004) Introgression of salttolerance from somatic hybrids between common wheat and Thinopyrum ponticum. Plant Sci 167:773-779

Chinnusamy V, Zhu JK (2009) Epigenetic regulation of stress responses in plants. Curr Opin Plant Biol 12:133-139

Das-Chatterjee A, Goswami L, Maitra S, Dastidar KG, Ray S, Majumder AL (2006) Introgression of a novel salt-tolerant L-myo-inositol 1-phosphate synthase from Porteresia coarctata (Roxb.) Tateoka (PCINO1) confers salt tolerance to evolutionary diverse organisms. FEBS Lett 580:3980-3988

Doerfler W (2011) Epigenetic consequences of foreign DNA insertions: de novo methylation and global alterations of methylation patterns in recipient genomes. Rev Med Virol 21:336-346

Hochholdinger F, Hoecker N (2007) Towards the molecular basis of heterosis. Trends Plant Sci 12:427-432

Horie T, Hauser F, Schroeder J (2009) HKT transporter-mediated salinity resistance mechanisms in Arabidopsis and monocot crop plants. Trends Plant Sci 14:660-668

Kato Y, Henry A, Fujita D, Katsura K, Kobayashi N, Serraj R (2011) Physiological characterization of introgression lines derived from an indica rice cultivar, IR64, adapted to drought and water-saving irrigation. Field Crop Res 123:130-138

King IP, Forster BP, Law CC, Cant KA, Orford SE, Gorham J, Reader S, Miller TE (1997) Introgression of salt-tolerance genes from Thinopyrum bessarabicum into wheat. New Phytol 137:75-81 
Lippman ZB, Zamir D (2007) Heterosis: revisiting the magic. Trends Genet 23:60-66

Liu B, Zhao R, Piao H, Zhao F, Zhao J (1999) Production and molecular characterization of rice lines with introgressed traits from a wild species Zizania latifolia (Griseb.). J Genet Br 53:279-284

Liu Z, Wang Y, Shen Y, Guo W, Hao S, Liu B (2004) Extensive alterations in DNA methylation and transcription in rice caused by introgression from Zizania latifolia. Plant Mol Biol 54:571-582

Livak KJ, Schmittgen TD (2001) Analysis of relative gene expression data using real-time quantitative PCR and the 2-[Delta][Delta] CT method. Methods 25:402-408

Lukens LN, Zhan S (2007) The plant genome's methylation status and response to stress: implications for plant improvement. Curr Opin Plant Biol 10:317-322

Lutts S, Kinet J, Bouharmont J (1996) NaCl-induced senescence in leaves of rice (Oryza sativa L.) cultivars differing in salinity resistance. Ann Bot 78:389

Martínez-Atienza J, Jiang X, Garciadeblas B, Mendoza I, Zhu JK, Pardo JM, Quintero FJ (2007) Conservation of the salt overly sensitive pathway in rice. Plant Physiol 143:1001-1012

Munns R, Tester M (2008) Mechanisms of salinity tolerance. Annu Rev Plant Biol 59:651-681

Negrão S, Courtois B, Ahmadi N, Abreu I, Saibo N, Oliveira M (2011) Recent updates on salinity stress in rice: from physiological to molecular responses. Crit Rev Plant Sci 30:329-377

Ren ZH, Gao JP, Li LG, Cai XL, Huang W, Chao DY, Zhu MZ, Wang ZY, Luan S, Lin HX (2005) A rice quantitative trait locus for salt tolerance encodes a sodium transporter. Nat Genet 37:1141-1146

Shan X, Liu Z, Dong Z, Wang Y, Chen Y, Lin X, Long L, Han F, Dong Y, Liu B (2005) Mobilization of the active MITE transposons mPing and Pong in rice by introgression from wild rice (Zizania latifolia Griseb.). Mol Biol Evol 22:976-990

Shi H, Quintero FJ, Pardo JM, Zhu JK (2002) The putative plasma membrane $\mathrm{Na}^{+} / \mathrm{H}^{+}$antiporter SOS1 controls long-distance $\mathrm{Na}^{+}$transport in plants. Plant Cell 14:465-477

Singh S, Mackill DJ, Ismail AM (2009) Responses of SUB1 rice introgression lines to submergence in the field: yield and grain quality. Field Crop Res 113:12-23

Soltis PS, Soltis DE (2009) The role of hybridization in plant speciation. Annu Rev Plant Biol 60:561-588

Sripinyowanich S, Klomsakul P, Boonburapong B, Bangyeekhun T, Asami T, Gu H, Buaboocha T, Chadchawan S (2010) Exogenous ABA induces salt tolerance in indica rice (Oryza sativa L.): The role of OSP5CS1 and OSP5CR gene expression during salt stress. Environ Exp Bot, in press

Wang N, Wang H, Zhang D, Wu Y, Ou X, Liu S, Dong Z, Liu B (2010) Transpositional reactivation of the Dart transposon family in rice lines derived from introgressive hybridization with Zizania latifolia. BMC Plant Biol 10:190

Wang S, Zheng W, Ren J, Zhang C (2002) Selectivity of various types of salt-resistant plants for $\mathrm{K}^{+}$over $\mathrm{Na}^{+}$. J Arid Environ 52:457-472

Wang YM, Dong ZY, Zhang ZJ, Lin XY, Shen Y, Zhou D, Liu B (2005) Extensive de novo genomic variation in rice induced by introgression from wild rice (Zizania latifolia Griseb.). Genetics 170:1945-1956

Whitney KD, Randell RA, Rieseberg LH (2010) Adaptive introgression of abiotic tolerance traits in the sunflower Helianthus annuus. New Phytol 187:230-239

Zhang X, Zhou S, Fu Y, Su Z, Wang X, Sun C (2006) Identification of a drought tolerant introgression line derived from Dongxiang common wild rice (O. rufipogon Griff.). Plant Mol Biol 62:247-259

Zhao S, Xu C, Zou Q, Q M (1994) Improvements of method for MDA measurement. Plant Physiol Commun 30:207-210

Zhu JK (2003) Regulation of ion homeostasis under salt stress. Curr Opin Cell Biol 6:441-445

doi:10.1186/1939-8433-5-36

Cite this article as: Yang et al: Heritable alteration in salt-tolerance in rice induced by introgression from wild rice (Zizania latifolia). Rice 2012 5:36.

\section{Submit your manuscript to a SpringerOpen ${ }^{\circ}$ journal and benefit from:}

- Convenient online submission

- Rigorous peer review

- Immediate publication on acceptance

- Open access: articles freely available online

- High visibility within the field

- Retaining the copyright to your article

Submit your next manuscript at $\gg$ springeropen.com 